\title{
IDENTIFICACIÓN DE MICROORGANISMOS BIORREMEDIADORES DE SUELOS AGRÍCOLAS DEL NORTE DE ANTIOQUIA PARA DEGRADACIÓN DEL CLORPIRIFOS
}

\author{
Marta Lucia Hernandez Angel ${ }^{1}$, Ena Patricia Lopez ${ }^{2}$, María Camila Jaramillo Granda ${ }^{3}$, Anlly Paola Posada \\ Usuga $^{4}$ \\ 1 Magister en ingeniería Ambiental, Instructora Sena Centro textil y de gestión industrial, mhernan- \\ dez@sena.edu.co. \\ 2 Magister en química \\ 3 Tecnologo en química aplicada a la industria \\ 4 Tecnologo en química aplicada a la industria
}

\begin{abstract}
RESUMEN
En los últimos años se ha encontrado cantidad de agroquímicos acumulados en suelos agrícolas que los vuelven infértiles, disminuye la calidad de los productos alimenticios, contaminan el suelo y aguas subterráneas. Un agroquímico utilizado de manera indiscriminada es el clorpirifos, principal producto de hidrólisis el 3,5,6-tricloro-2-piridinol.

En este proyecto se unen dos estrategias de biorremediación para mitigar la problemática de los agroquímicos, se realiza análisis sobre capacidades de degradación de microorganismos del suelo contaminado, identificación para potenciar la facultad de estos, determinación de concentraciones viables para realizar biodegradación en los suelos agrícolas y disminuir la tasa de contaminación en el ecosistema y los niveles de intoxicación al ser humano. El objetivo de esta investigación es analizar y evidenciar la biodegradación del pesticida clorpirifos a diferentes concentraciones de microorganismos y solución de nutrientes, con el propósito de nivelar la sobrecarga de agroquímicos y evitar una mayor contaminación en el suelo, cultivos y aguas subterráneas.
\end{abstract}

Palabras clave: Recuperación de suelos, contaminación de suelos agrícolas, organismos biorremediadores, agroquímicos.

Recibido: 6 de septiembre de 2020. Aceptado: 7 de Diciembre de 2020

Received: September 6, 2020. Accepted: December 7, 2020

\section{IDENTIFICATION OF AGRICULTURAL SOIL BIOREMEDIATION MICROORGANISMS IN NORTHERN AN- TIOQUIA FOR CHLORPYRIFOS DEGRADATION}

\begin{abstract}
In recent years, a quantity of accumulated agrochemicals has been found in agricultural soils that make them infertile, decrease the quality of food products, and contaminate the soil and groundwater. An agrochemical used indiscriminately is chlorpyrifos, the main hydrolysis product 3,5,6-trichloro-2-pyridinol.

In this project, two bioremediation strategies are combined to mitigate the problem of agrochemicals, analyzes are carried out on the degradation capabilities of microorganisms in contaminated soil, identification to enhance their ability, determination of viable concentrations to carry out biodegradation in agricultural soils and decrease the pollution rate in the ecosystem and the levels of human poisoning.

The objective of this research is to analyze and demonstrate the biodegradation of the pesticide chlorpyrifos at different concentrations of microorganisms and nutrient solutions, with the purpose of leveling the overload of agrochemicals and avoiding further contamination in the soil, crops and groundwater.
\end{abstract}

Keywords: Soil recovery, agricultural soil contamination, bioremediation organisms, agrochemicals

Cómo citar este artículo: M. Hernandez, E. Lopez, M. Jaramillo, A. Posada. "Identificación de microorganismos biorremediadores de suelos agrícolas del norte de Antioquia para degradación del clorpirifos", Revista Politécnica, vol.16, no.32 pp.96-110, 2020. DOI:10.33571/rpolitec.v16n32a9 


\section{INTRODUCCIÓN}

La zona norte de Antioquia se caracteriza por sus cultivos agrícolas, entre los cuales se destacan papa, fríjol, frutales (uvas, guayaba, aguacate, mora, lulo, tomate de árbol, uchuva, entre otras) y de hortalizas (zanahoria, lechuga, espinaca, cilantro, entre otras).

Alli el suelo tiene, en su gran mayoría, características de suelos orgánicos, su espacio geográfico presenta procesos de urbanización poco densos lo que lo hace una zona rica en explotación, principalmente ganadera y agrícola. El clima es frío, presentando una temperatura media mensual de $14,2^{\circ} \mathrm{C}$, la máxima es de $16^{\circ} \mathrm{C}$ y la mínima de $12^{\circ} \mathrm{C}$. (CMGRD, 2016) Estos suelos agrícolas son constantemente fumigados con clorpirifos para controlar diversas plagas

El clorpirifos es un insecticida organofosforado, insoluble en agua, con una toxicidad alta, liposoluble y altamente volátil según condiciones de temperatura. Estas características facilitan su absorción y permiten una vida media en el suelo de 10-120 días; si se tiene en cuenta que las aspersiones en estos cultivos se realizan cada 45 días, aproximadamente, se crea una problemática por bioacumulación.

Como plan de mitigación de este problema se plantean dos estrategias de biorremediación, la atenuación natural que corresponde a activar las poblaciones microbianas propias de los suelos que poseen unas características de adaptación a los plaguicidas y colocarles las condiciones que permitan que se multipliquen y así poder desarrollar los procesos para una biorremediación. Con lo que se logra una transformación parcial o total de los plaguicidas. (Viñas y col, 2001; Nápoles, 2005).

Por otro lado, Viñas y col (2001) y Nápoles (2005) indican que cuando se realiza una biorremediación dirigida se realizan los procesos de bioestimulación, que es el proceso con nutrientes que estimulan el crecimiento de los microorganismos, y la bioaumentación que corresponde a la propagación previa en laboratorio de los microorganismos identificados como biorremediadores para agregarlos al suelo e incrementar la población microbiana y acelerar el proceso natural de descontaminación de los suelos.

Se conoce que las bacterias que presentan una mayor asociación a la degradación de compuestos organofosforados son: Pseudomonas, Serratia, Bacillus, Rhodococcus y Streptomyces, Los microorganismos de carácter fúngico que se presentan un comportamiento de degradación ante los compuestos organofosforados son: Phanerochaete, Aspergillus, Absidia, Rhizopus, Penicillium.

Los microorganismos realizan múltiples acciones en el suelo, al permitir las reacciones que hacen que los nutrientes queden en estado biodisponible y la interacción con las raíces que aseguren la disponibilidad y movilidad de estos. Además, son responsables de la estructura, control de organismos patógenos, degradación de contaminantes diversos en el suelo". (González, 2019)

En esta investigación se pretende evidenciar la biodegradación del pesticida a diferentes concentraciones de microorganismos y solución de nutrientes adicionadas, con el fin de disminuir la carga de agroquímicos en los suelos con utilidad agrícola.

\section{MATERIALES Y METODO}

\subsection{Aislamiento microbiano}

Se seleccionó una muestra de suelo que es utilizado para la actividad agrícola, esta se buscó colocarla en condiciones aisladas en un recipiente que fue debidamente adecuado para garantizar condiciones normales de humedad y temperatura (entre $11^{\circ} \mathrm{C}$ y $22^{\circ} \mathrm{C}$ humedad $67 \%$ ), a este se le agregó $83,33 \mu \mathrm{L}$ de Clorpirifos a una concentración de 200 ppm, que previamente fue diluida con agua desionizada en un volumen de $50 \mathrm{~mL}$. Esta muestra fue posteriormente homogenizada, sellada y almacenada durante 30 días.

En el procedimiento que busca el aislamiento de los microorganismos se preparó una solución de $200 \mathrm{~mL}$ con medio mínimo M9 $(6 \mathrm{~g}$ de fosfato ácido de sodio hidratado, $3 \mathrm{~g}$ de fosfato ácido de potasio, $4 \mathrm{~g}$ de cloruro de amonio, 0,5 $\mathrm{g}$ de cloruro de sodio, 0,25 de sulfato de manganeso heptahidratado, 0,0168 $\mathrm{g}$ de 
cloruro de calcio hidratado) y se utilizaron $83,33 \mu \mathrm{L}$ de Clorpirifos a $200 \mathrm{ppm}$, como única fuente de carbono. (Marín L. \& Jaramillo Colorado, 2015).

En tres tubos de ensayo, se preparó la solución y en cada tubo se colocó $9 \mathrm{~mL}$ de la solución previamente preparada con medio mínimo (M9). A parte, en un erlenmeyer, se depositaron $10 \mathrm{~g}$ de suelo y se adicionaron $90 \mathrm{~mL}$ de la solución de medio mínimo (M9), con esta última se realizó una dilución progresiva de concentración hasta un factor de 10-4 para el cultivo de los microorganismos.

En el proceso de réplica microbiana se preparó un agar nutritivo, para la incubación en 15 cajas Petri de los microorganismos obtenidos de los factores de dilución previamente cultivados que se realizó a $37^{\circ} \mathrm{C}$, con una humedad de $65 \%$ después de 24 horas. Se escogieron 10 colonias de microorganismos que habían crecido bajo condiciones de buena propagación y mostrando alta densidad poblacional, fueron usados especialmente la inoculación de los microorganismos extraídos de las diluciones 10-3 y 10-4. A estas colonias de microorganismos se les realizó un repique bajo concentraciones de Clorpirifos, para verificar la capacidad de ellos a la degradación de este plaguicida.

\subsection{Caracterización de microorganismos}

Se realizaron las pruebas de caracterización correspondientes tanto para bacterias (tinción de Gram, catalasa, oxidasa, prueba de metabolismo respiratorio, pruebas con medios selectivos) como para hongos (análisis taxonómicos). La tinción de Gram se realizó para clasificar a las bacterias en Gram (+) y Gram (-) según la capacidad de retención del colorante cristal violeta durante la decoloración con alcohol-acetona. Se realizó la prueba de citocromo oxidasa que sirvió para determinar la presencia de enzimas oxidasas.

Finalmente, se realizó un análisis taxonómico a un microorganismo al que se le observó una morfología de hongo, ya que era único en lo observado y se realizó el montaje por imprenta con cinta translúcida.

Las pruebas con medios selectivos se realizaron sólo con 5 colonias, que previamente fueron seleccionadas por presentar buen crecimiento bajo concentraciones de Clorpirifos, en Cetrimide y VRBD.

\subsection{Caracterización del suelo.}

Conociendo las condiciones y características del suelo y de las concentraciones de diferentes macronutrientes y micronutrientes presentes en el mismo, se identificaron los parámetros nutricionales que requieren los microorganismos para ser estimulados.

Previamente, para realizar esta determinación, se llevó a cabo el respectivo muestreo de suelo agrícola en la zona norte de Antioquia, las muestras se tomaron al azar luego de cuartear el terreno y se tomaron muestras de 10 a $20 \mathrm{~cm}$ de profundidad.

Los análisis del suelo se realizaron con las técnicas y resultados que se presentan a continuación. 
Tabla 1. Tabla de pruebas pertinentes para la caracterización de suelo agrícola.

\begin{tabular}{|c|c|}
\hline PARÁMETRO & TIPO DE PRUEBA \\
\hline $\mathrm{pH}$ & Potenciométrico agua 1:2 \\
\hline Porcentaje de humedad & Gravimétrico \\
\hline Fósforo ppm & Bray II modificado \\
\hline Porcentaje de carbono orgánico & Digestión vía húmeda Walkley-black \\
\hline $\begin{array}{l}\text { Capacidad de intercambio catió- } \\
\text { nico } \mathrm{meq} / 100 \mathrm{~g} \text { suelo }\end{array}$ & Extracción acetato de amonio $1 \mathrm{~N}$, método IGAC \\
\hline Calcio cmol/Kg suelo & Extracción acetato de amonio $1 \mathrm{~N}$ absorción atómica \\
\hline Magnesio cmol/Kg suelo & Extracción acetato de amonio $1 \mathrm{~N}$ absorción atómica \\
\hline Potasio $\mathrm{cmol} / \mathrm{Kg}$ suelo & Extracción acetato de amonio $1 \mathrm{~N}$ absorción atómica \\
\hline Zinc ppm & Mehlich III espectrofotometría de absorción atómica \\
\hline Hierro ppm & $\begin{array}{l}\text { Mehlich III espectrofotometría de absorción atómica } \\
\text { Mehlich III espectrofotometría de absorción atómica }\end{array}$ \\
\hline Cobre ppm & Mehlich III espectrofotometría de absorción atómica \\
\hline Manganeso ppm & Mehlich III espectrofotometría de absorción atómica \\
\hline$\%$ Arena 2 a $0,05 \mathrm{~mm}$ & Bouyoucos \\
\hline$\%$ Arcillas menor a $0,02 \mathrm{~mm}$ & Bouyoucos \\
\hline \%Limo 0,05 a $0,002 \mathrm{~mm}$ & Bouyoucos \\
\hline
\end{tabular}

Hernandez, A. M., (2019). Laboratorio de servicios tecnológicos del SENA. Análisis de suelos-ECAS, LST02214.

\subsection{Diseño experimental}

El diseño experimental, realizado para esta muestra de suelo agrícola, se realizó con porciones de $1.0 \mathrm{~kg}$ de suelo. Este fue recolectado donde se cultivan hortalizas y es fumigado con plaguicidas entre los que se encuentran, principalmente, el Clorpirifos. Las muestras para los ensayos fueron obtenidas de tres puntos de la zona agrícola previamente establecida, el diseño experimental planteado fue de 23 , con tres niveles de concentración y dos factores que son considerados fundamentales para el crecimiento de los microorganismos:

- Nutrientes (con esta solución se busca aplicar la estimulación para que los microorganismos cuenten con los macro y micronutrientes esenciales para poder realizar el proceso de biorremediación)

- Microorganismos (medio líquido con microorganismos para generar Bioaumentación, obtenidos de los aislamientos previamente realizados de la zona de cultivo) 
Estos factores se usaron en niveles o dosis diferentes como se presenta en la tabla siguiente y fueron realizados por réplica.

Tabla 2. Niveles de los factores aplicados en ensayos pilotos.

\begin{tabular}{|c|c|}
\hline $\begin{array}{c}\text { DOSIS DE MICROORGANISMOS } \\
\text { (Bioaumentación) }\end{array}$ & $\begin{array}{c}\text { DOSIS DE NUTRIENTES } \\
\text { (Bioestimulación) }\end{array}$ \\
\hline $0 \mathrm{ml}$ & $0 \mathrm{~mL}$ \\
\hline $2 \mathrm{ml}$ & $2 \mathrm{~mL}$ \\
\hline $4 \mathrm{ml}$ & $4 \mathrm{~mL}$ \\
\hline
\end{tabular}

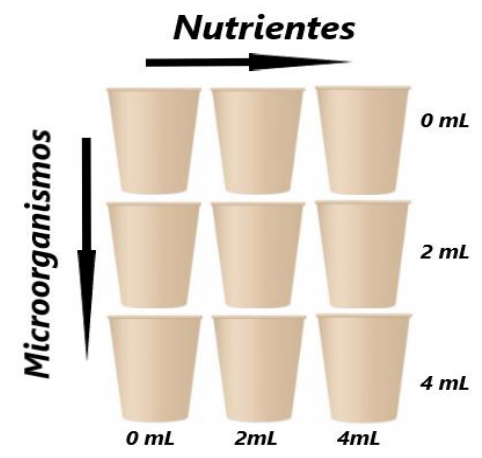

Figura 1: Boceto del diseño experimental.

En primera instancia, se preparó un medio líquido de microorganismos con las cepas que se tenían previamente seleccionadas de la siguiente manera: esterilizar el caldo nutritivo en autoclave a una temperatura de $121^{\circ} \mathrm{C}$ durante 20 minutos, dejar reposar hasta que su temperatura disminuya y agregar las cepas purificadas, triturar las cepas antes de añadirlas en el caldo nutritivo y luego introducirlas al erlenmeyer que contenga el caldo nutritivo, finalmente se llevan a un proceso de agitación en un shaker a 37으 y 240 RPM hasta que esté homogéneo por 24 horas.

La solución de nutrientes realizada fue la establecida en la tabla 3, por experiencia de los investigadores, a esta se le agrego melaza como fuente de energía para los microorganismos.

Tabla 3. Micro y macronutrientes usados (Betancur et al., 2011, 5)

\begin{tabular}{|l|l|}
\hline \multicolumn{1}{|c|}{ MACRONUTRIENTES } & \multicolumn{1}{c|}{ MICRONUTRIENTES } \\
\hline $271.9 \mathrm{~g}$ de Fosfato de potasio & $6.355 \mathrm{~g}$ de Ácido bórico \\
\hline $213.7 \mathrm{~g}$ Nitrato de potasio & $0.640 \mathrm{~g}$ de Sulfato de cobre \\
\hline $151.2 \mathrm{~g}$ Nitrato de sodio & $16.295 \mathrm{~g}$ de Sulfato de manganeso \\
\hline
\end{tabular}




\begin{tabular}{|l|l|}
\hline \multicolumn{1}{|c|}{ MACRONUTRIENTES } & \multicolumn{1}{c|}{ MICRONUTRIENTES } \\
\hline $247.4 \mathrm{~g}$ Sulfato de magnesio & $6.550 \mathrm{~g}$ de sulfato de zinc \\
\hline $400 \mathrm{~g}$ Nitrato de calcio & $0.985 \mathrm{~g}$ de Molibdato de sodio \\
\hline
\end{tabular}

Esta solución nutritiva se prepara en solución A, B, C, D. la Solución A. Se pesa el fosfato de potasio, Nitrato de potasio, Nitrato de sodio y sulfato de magnesio; se diluye cada uno de los reactivos en dos litros de agua, se juntan y se completa a un volumen de 10 litros. La Solución B. Se pesa Nitrato de calcio, se diluye y lleva a un volumen de 10 litros. Para la solución $\mathrm{C}$, se pesa el ácido bórico, el sulfato de cobre y el sulfato de manganeso, cada uno se diluye en agua y finalmente se mezclan y llevan a un volumen de 1 litro. La solución D. Se pesa el cloruro férrico, el EDTA y se diluye en $500 \mathrm{ml}$ de agua y finalmente se mezclan y empacan en un frasco opaco cubierto con papel aluminio. (Betancur et al., 2011).

Para la preparación de la solución para realizar la bioestimulación para 10 litros se usa: $100 \mathrm{ml}$ de solución A en 1 litro, $2 \mathrm{~mL}$ de solución C en $200 \mathrm{~mL}, 2 \mathrm{~mL}$ de solución D en $200 \mathrm{ml}, 100 \mathrm{ml}$ de solución B en 1 litro y $10 \mathrm{~g}$ de melaza. (Betancur et al., 2011).

Para las condiciones nutritivas del suelo según análisis realizado, se ajustan los macro y microelementos del suelo que garanticen que los microorganismos tengan una bioestimulación con estos nutrientes y puedan propagarse en cantidades suficientes para bioaumentar la población. Estos fueron tres semanas muestreados, una vez cada semana y por medio de cromatografía de gases acoplado a masas, cuantificada la cantidad de clorpirifos en cada muestra.

\section{RESULTADOS Y DISCUSION}

Como resultado de los aislamientos e inoculación microbiana, se logró observar un crecimiento notorio en la totalidad de las cajas, como se evidencia en la figura 2.

De este aislamiento se seleccionaron 10 colonias (figura 3). para realizar posteriormente un repique microbiano, pero esta vez bajo concentraciones de Clorpirifos. Esto con el fin de hacer una purificación de microorganismos y una obtención de ellos para generar la bioaumentación.

El resultado de uno de ellos fue el crecimiento de un microorganismo con morfología de hongo. (figura 4).

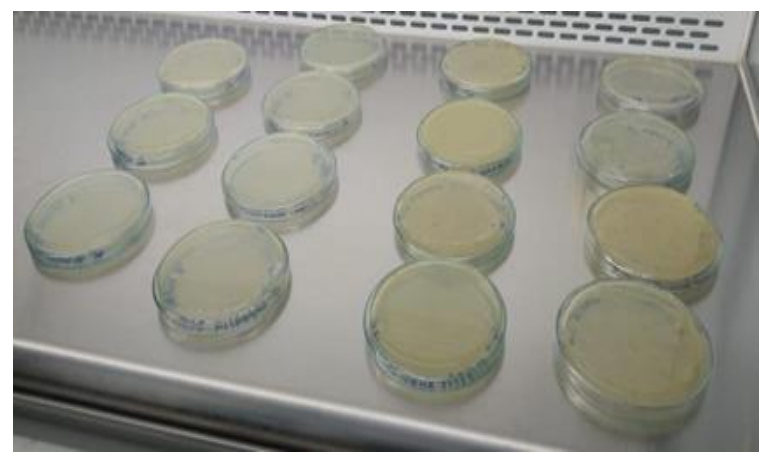

Figura 2: Resultados de los aislamientos microbianos. 


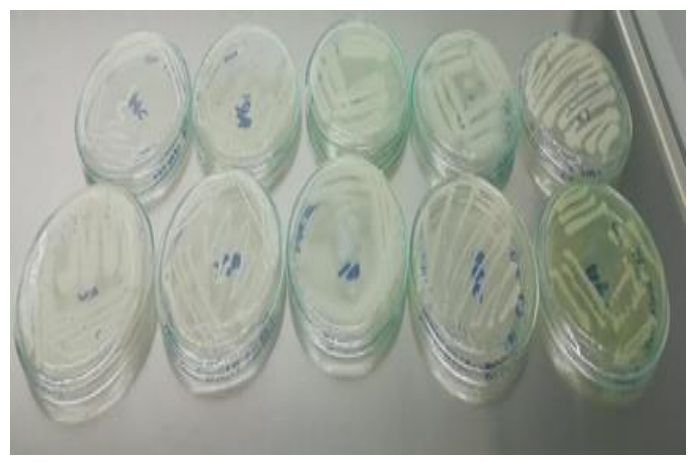

Figura 3: Selección de microorganismos para realizar el repique microbiano bajo concentraciones de Clorpirifos.

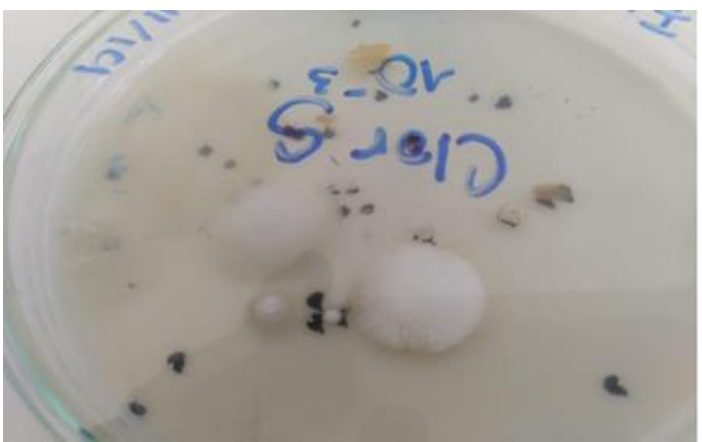

Figura 4: Microorganismo con morfología de hongo evidenciado en la purificación del microorganismo.

Se realizó una caracterización macroscópica de 10 colonias que son el resultado de un aislamiento por diluciones seriadas. Ver resultado en la tabla 4

Tabla 4: Caracterización macroscópica realizada a las 10 colonias de microorganismos seleccionados previamente.

\begin{tabular}{|c|c|c|}
\hline MORFOTIPO & CARACTERÍSTICA & DILUCIÓN \\
\hline CLOR 1 & Blanca e irregular & $10^{-3}$ \\
\hline CLOR 2 & De poco color, irregular-rizoide & $10^{-4}$ \\
\hline CLOR 3 & Color opaco, mediana, circular & $10^{-4}$ \\
\hline CLOR 4 & Color oscuro, mediana e irregular & $10^{-4}$ \\
\hline CLOR 5 & Blanca, pequeña, circular & $10^{-4}$ \\
\hline CLOR 6 & Blanca, pequeña, circular & $10^{-4}$ \\
\hline CLOR 7 & Blanca, pequeña, circular & $10^{-3}$ \\
\hline
\end{tabular}


Del repique microbiano bajo concentraciones de Clorpirifos se realizó un segundo repique con el fin de purificar y preservar los microorganismos; a estos morfotipos se les nombra de la siguiente manera:

"CLOR \#.2”. Ejemplo, “CLOR 1.2”.

Se realizaron pruebas de caracterización microscópica, cuatro de ellas no se lograron identificar debido a su alta carga de microorganismos.

Con el fin de identificar mejor los microorganismos, y con la ayuda de los resultados de las pruebas anteriores, se pudieron identificar algunas familias de bacterias. Los resultados se evidencian en la tabla 5.

Tabla 5: Resultados de pruebas de caracterización microbiana

\begin{tabular}{|c|c|c|c|c|c|}
\hline MORFOTIPO & $\begin{array}{l}\text { MICROORGAN- } \\
\text { ISMO SEGÚN SU } \\
\text { FORMA }\end{array}$ & $\begin{array}{l}\text { TINCIÓN } \\
\text { DE GRAM }\end{array}$ & $\begin{array}{l}\text { CATA- } \\
\text { LASA }\end{array}$ & $\begin{array}{l}\text { MEDICIÓN } \\
\text { CITOCROMO } \\
\text { OXIDASA }\end{array}$ & $\begin{array}{l}\text { POSIBLE ORIGEN FA- } \\
\text { MILIAR BACTERIANO }\end{array}$ \\
\hline CLOR 1.2 & BACILOS & GRAM - & POSITIVA & POSITIVO & $\frac{\text { PSEUDOMONA- }}{\underline{D A C E A E}}$ \\
\hline CLOR 2.2 & INDEFINIDO & GRAM - & NEGATIVA & NEGATIVO & INDEFINIDO \\
\hline CLOR 3.2 & INDEFINIDO & GRAM - & POSITIVA & POSITIVO & INDEFINIDO \\
\hline CLOR 4.2 & INDEFINIDO & GRAM - & POSITIVA & NEGATIVO & INDEFINIDO \\
\hline CLOR 5.2 & INDEFINIDO & GRAM - & NEGATIVA & NEGATIVO & INDEFINIDO \\
\hline CLOR 6.2 & ESTREPTOCOCOS & GRAM + & NEGATIVA & NEGATIVO & $\frac{\text { STREPTOCOCCA- }}{\text { CEAE }}$ \\
\hline CLOR 7.2 & cocos & GRAM - & NEGATIVA & NEGATIVO & $\frac{\text { ENTEROBACTERI- }}{\underline{A C E A E}}$ \\
\hline CLOR 8.2 & cocos & GRAM - & POSITIVA & POSITIVO & $\frac{\text { PSEUDOMONA- }}{\underline{D A C E A E}}$ \\
\hline CLOR 9.2 & $\begin{array}{l}\operatorname{COCOS} Y B A- \\
\text { CILOS }\end{array}$ & GRAM - & POSITIVA & NEGATIVO & $\frac{\text { ENTEROBACTERI- }}{\text { ACEAE }}$ \\
\hline CLOR 10.2 & ESTREPTOCOCOS & GRAM + & NEGATIVA & POSITIVO & $\frac{\text { STREPTOCOCCA- }}{\underline{C E A E}}$ \\
\hline
\end{tabular}

En la prueba de metabolismo respiratorio se evidenció que cinco de los morfotipos resultaron con características microaerofílicas, lo que indica que son microorganismos que precisan niveles muy inferiores de oxígeno a los que se encuentran en la atmósfera de la tierra. Ver resultado en tabla 4

Tabla 6: Resultado de la prueba de metabolismo respiratorio (propia) 


\begin{tabular}{|c|c|}
\hline MORFOTIPO & TIPO DE MICROORGANISMO EN MEDIO LÍQUIDO \\
\hline CLOR 1.2 & MICROAEROFÍLICO \\
\hline CLOR 2.2 & ANAEROBIA \\
\hline CLOR 3.2 & MICROAEROFÍLICO \\
\hline CLOR 4.2 & MICROAEROFÍLICO \\
\hline CLOR 5.2 & ANAEROBIA \\
\hline CLOR 6.2 & ANAEROBIA \\
\hline CLOR 7.2 & ANAEROBIA \\
\hline CLOR 8.2 & MICROAEROFÍLICO \\
\hline CLOR 9.2 & MICROAEROFÍLICO \\
\hline CLOR 10.2 & ANAEROBIA \\
\hline
\end{tabular}

\subsection{Selección de microorganismos:}

Como resultado de las pruebas en medios selectivos, se seleccionaron cinco colonias de bacterias (figura 5), las cuales se sembraron en Cetrimide, VRBD y manitol.

En el Agar selectivo manitol no se obtuvo crecimiento en ninguna de las cepas expuestas a dicho medio selectivo

De los aislamientos purificados, la cepa CLOR 8.2 presentó un comportamiento que muestra buen crecimiento, pero cuando fue cultivado en medios selectivos que permitían establecer el potencial degradador, no evidenció crecimiento.

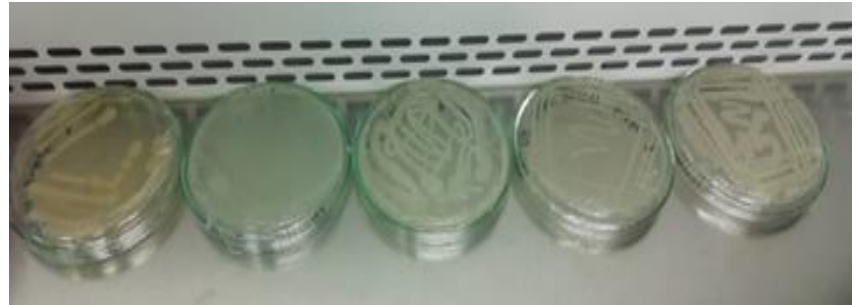

Figura 5: Grupo de bacterias seleccionadas para pruebas en medios selectivos. 
Se evidenció crecimiento en el medio de cultivo Cetrimide, que es selectivo para pseudomona, en los morfotipos CLOR 3,2, CLOR 6,2 Y CLOR 9,2 y en VRBD, que es selectivo para coliformes, se evidenció crecimiento en el morfotipo CLOR 3,2 (figura 6).

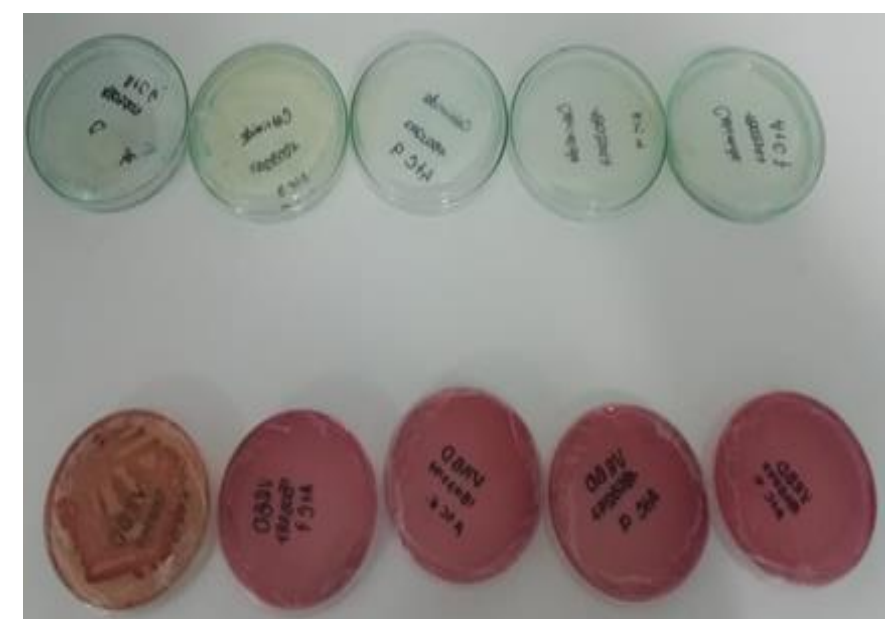

Figura 6: Medios selectivos Cetrimide y VRBD en los que se observó crecimiento bacteriano.

Se realizó una caracterización microscópica a las 4 cepas que presentaron crecimiento en los medios selectivos y se clasificaron en Cocos y Bacilos a aquellas cepas que crecieron en Agar Cetrimide y, en la cepa que presentó crecimiento en Agar VRBD, una clasificación de Bacilos.

Otros análisis realizados fueron pruebas de tinción de Gram, donde se obtuvo un resultado de Gram (+) para todas las muestras, a excepción del morfotipo CLOR 6,2,. Esto se puede observar en la tabla 7.

Tabla 7: Resultado de pruebas de caracterización microscópica.

\begin{tabular}{|c|c|c|c|}
\hline MEDIO DE CULTIVO & MORFOTIPO & $\begin{array}{c}\text { MICROORGANISMO SEGÚN } \\
\text { SU FORMA }\end{array}$ & $\begin{array}{c}\text { TINCIÓN DE } \\
\text { GRAM }\end{array}$ \\
\hline Cetrimide & Clor 3.2 & COCOS Y BACILOS & GRAM - \\
\hline Cetrimide & Clor 6.2 & COCOS Y BACILOS & GRAM + \\
\hline Cetrimide & Clor 9.2 & COCOS Y BACILOS & GRAM - \\
\hline VRBD & Clor 3.2 & BACILOS & GRAM - \\
\hline
\end{tabular}

En el análisis taxonómico realizado al microorganismo con morfología de hongo se logró observar hifas y levaduras, como se evidencia en la morfología básica de los hongos filamentosos Aspergillus flavus, los cuales habitan en el heno y el compostaje. (figura 7). 


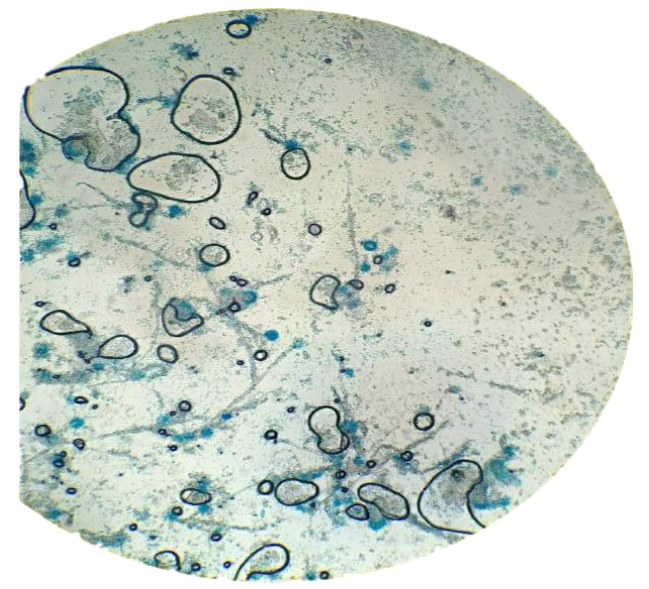

Figura 7: Taxonomía de microorganismo con morfología de hongo, observado en el lente $100 \mathrm{X}$

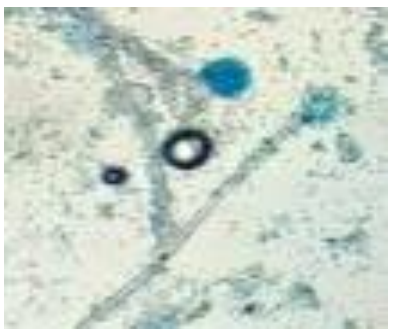

Figura 8: Acercamiento a las hifas y levaduras del Hongo.

Como resultado de los análisis del suelo, se obtuvieron los datos presentados en la tabla 8 . Estos permitieron identificar las condiciones de requerimientos de los macro y micronutrientes para asegurar los procesos de estos microorganismos

En la preparación de la solución de nutrientes, los materiales más usados son sales solubles en agua que permiten su conservación y preservación bajo condiciones controladas de luz y temperatura. Con esta se buscó ajustar los macronutrientes y micronutrientes necesarios para la biorremediación según diseño experimental, estos ensayos se realizaron por réplica.

Tabla 8. Resultados de la caracterización del suelo.

\begin{tabular}{|l|c|}
\hline \multicolumn{1}{|c|}{ PARÁMETRO } & RESULTADO \\
\hline pH & 6,25 \\
\hline Porcentaje de humedad & 14,1 \\
\hline Fósforo ppm & 3,0 \\
\hline Porcentaje de carbono orgánico & 27,7 \\
\hline Capacidad de intercambio catiónico meq/100g suelo & 48,8 \\
\hline Calcio cmol/Kg suelo & 8,7 \\
\hline Magnesio cmol/Kg suelo & 9,5 \\
\hline
\end{tabular}




\begin{tabular}{|l|c|}
\hline \multicolumn{1}{|c|}{ PARÁMETRO } & RESULTADO \\
\hline Potasio cmol/Kg suelo & 0,45 \\
\hline Zinc ppm & 19,9 \\
\hline Hierro ppm & 48,5 \\
\hline Cobre ppm & 4,8 \\
\hline Manganeso ppm & 43,3 \\
\hline \%Arena 2 a 0,05 mm & 68 \\
\hline \%Arcillas menor a 0,02mm & 28 \\
\hline \%Limo 0,05 a 0,002 mm & 4 \\
\hline
\end{tabular}

Hernandez, A. M., (2019). Laboratorio de servicios tecnológicos del SENA. Análisis de suelos-ECAS, LST-02214.

\subsection{Diseño experimental.}

En el desarrollo del diseño experimental, se usaron recipientes plásticos con tapas como se muestra en la figura 9 y en cada recipiente se colocó el material de suelo de las muestras de zonas de siembra de hortalizas con las correspondientes porciones de microorganismos en medio líquido y de nutrientes estos fueron colocados a unas condiciones de temperatura de $24^{\circ} \mathrm{C}$ y un nivel de humedad relativo de $65 \%$ en el laboratorio, en un ambiente favorable para su propagación.

En los ensayos realizados, el nivel de humedad de los suelos es un factor importante y para evitar que las muestras presentaran altos nivel de evaporación y se secaran cada dos días se le agregaban $3 \mathrm{ml}$ de agua destilada asegurando unas condiciones favorables para que los microorganismos pudieran replicarse y los procesos de los nutrientes fueran aprovechados en los procesos de estimulación y multiplicación de los microorganismos.

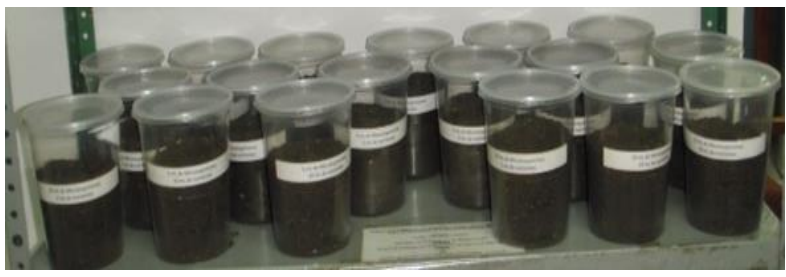

Figura 9. Montaje para ensayo de biorremediación por duplicado

Durante tres semanas, para poder realizar el seguimiento de las muestras se realizó la medición de Clorpirifos con un cromatógrafo de gases acoplado a masas, modelo GC 2010, marca Shimadzu y también, se hicieron algunos ensayos con suelos agrícolas libres de clorpirifos, que fueron tomadas en la misma finca en zona de cultivo de jardín.

Para la preparación de las muestras para los análisis de clorpirifos se tomaron $2 \mathrm{~g}$ de muestra de suelo se le agregaron $15 \mathrm{~mL}$ de una mezcla 1:1 de hexano: acetona (grado cromatográfico), se agitaron en un shaker por 12 horas a 240 RPM, posteriormente se dejaron decantar y se separó la parte orgánica realizando la cuantificación correspondiente. Zapata, M., \& María, G. (2005). 
En la gráfica siguiente se muestran para cada uno de los ensayos del diseño experimental planteado los porcentajes de degradación del clorpirifos en cada semana, donde $\mathrm{N}$ es la cantidad de nutrientes y $\mathrm{M}$ corresponde a la cantidad de microorganismos para cada uno de los ensayos.

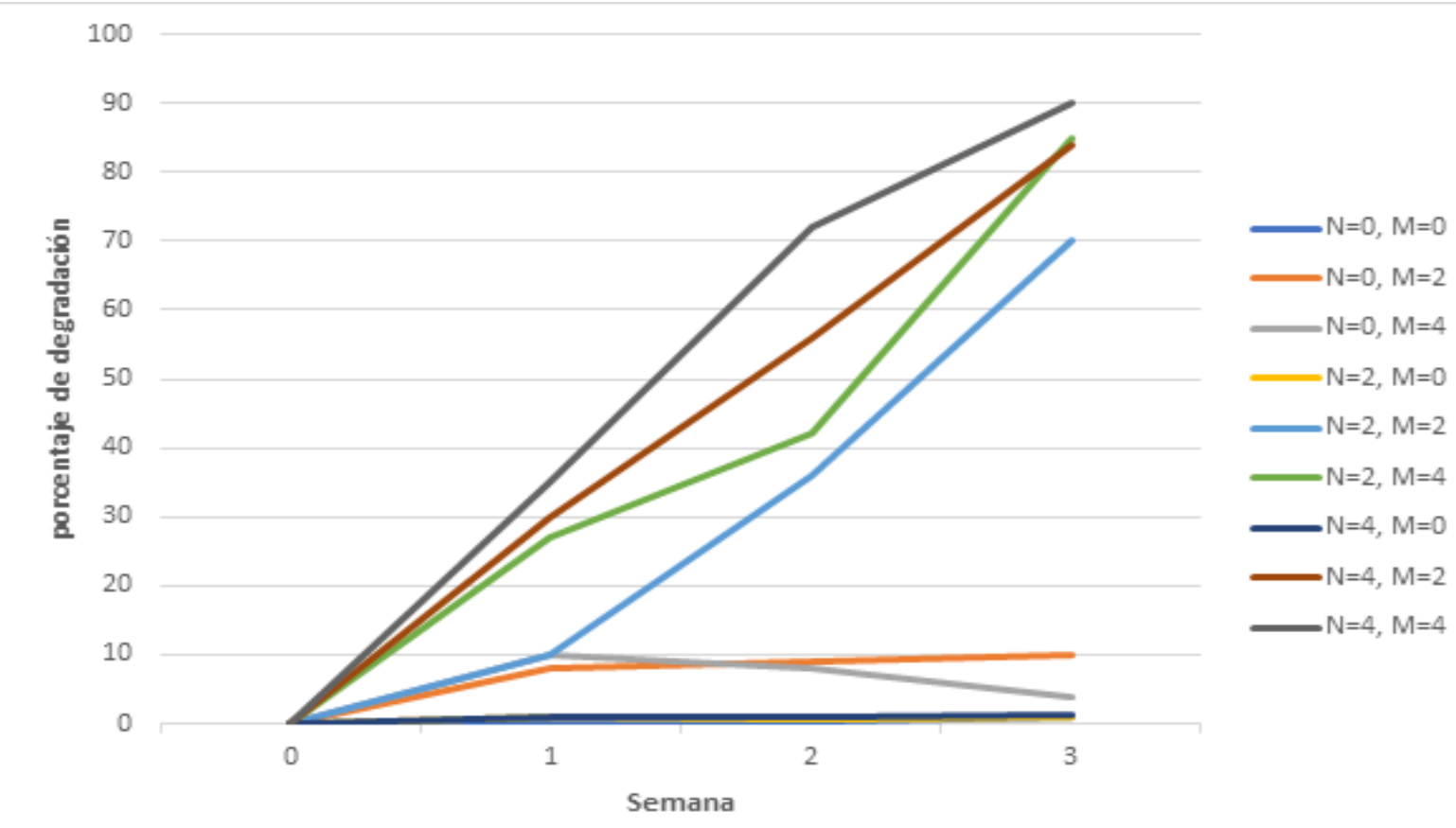

Figura 10. Gráfica de porcentaje de degradación del clorpirifos en los diferentes ensayos.

De la gráfica se identifica que los ensayos realizados con nutrientes, aunque fueran en cantidades altas (valores de 2 y $4 \mathrm{ml}$ de nutrientes), pero sin presencia de microorganismos presentaron una degradación baja indicando que los procesos de bioestimulación que se dan en este tipo de suelos es baja, indicando que la bioestimulación sola no es efectiva y además por la presencia de microorganismos que baja como se deduce de los procesos de propagación de los microorganismos previos a los ensayos.

Para los ensayos con microorganismos sin nutrientes se identifica que los procesos de reproducción de los microorganismos son muy bajos y por eso la degradación es muy baja. Indicando que los procesos de bioaumentación sola tampoco son los más eficientes.

Desde los resultados obtenidos se identifica que el ensayo con $4 \mathrm{ml}$ de nutrientes y $4 \mathrm{ml}$ de microorganismos presentó los mejores resultados, es importante resaltar que los microorganismos usados en la totalidad de ensayos fueron los obtenidos de ese suelo de cultivo de hortalizas en la zona de San Pedro del departamento de Antioquia y simplemente multiplicados en el laboratorio para obtenerlos en el medio líquido en condiciones y cantidades mayores para generar la bioaumentación. 


\section{CONCLUSIONES}

Tras analizar los resultados de las pruebas de caracterización, se observó la existencia de microorganismos compatibles con pseudomonas y Coliformes que utilizaban como su única fuente de carbono el Clorpirifos.

Se establece que la combinación de las técnicas de bioestimulación y bioaumentación fueron más efectivas en los procesos de biorremediación de los suelos agrícolas de zonas frías.

Para los ensayos con nutrientes y microorganismos la concentración de microorganismos y de nutrientes mayor muestra unos resultados muy buenos de degradación en las tres semanas de los ensayos indicando que este proceso es eficiente cuando se combinan nutrientes y microorganismos en las cantidades requeridas.

En los procesos de biorremediación involucrados de bioaumentación y bioestimulación las condiciones en las que se encuentran los microorganismos son decisivas para que estos procesos se realicen satisfactoriamente en tiempos mínimos.

Las cantidades de macro y micronutrientes, el $\mathrm{pH}$ acorde con el tipo de microorganismo, los factores externos como humedad y la capacidad de intercambio catiónico de los suelos son variables que favorecen y permiten optimizar la correcta biorremediación microbiana.

Es importante realizar este tipo de ensayos en zonas de cultivo directamente para identificar los cambios y afectaciones de otras variables en estos procesos, que no se hayan identificado previamente.

\section{AGRADECIMIENTOS.}

Agradecemos al SENA por la motivación para investigar y por brindar las instalaciones para los análisis de este proyecto. A Laura María Muñoz Echeverri, Ingeniera Biológica MSc Ciencias Biotecnología, por su valiosa colaboración y a Venus Verónica Olivares Santamaria, Harold Piedrahíta Areiza y Dayan Alejandro Herrera Álvarez por su importante participación en la ejecución de la metodología.

\section{REFERENCIAS BIBLIOGRÁFICAS}

[1] Viñas, M.; Sabaté, J.; Grifoll, M. Solanas, A.M. 2001. Ensayos de tratabilidad en la recuperación de suelos contaminados por la tecnología de la biorremediación. Residuos. Revista técnica. 59:78-82

[2] Nápoles, J. 2005. Ensayos de tratabilidad en suelos contaminados con petróleo. Tesis en opción al título de Máster en Biotecnología. Mención Ambiental. Universidad de Oriente, Santiago de Cuba

[3] González, A. (18 de julio de 2019). Microorganismos, los grandes desconocidos de nuestro suelo. Fertibox. https://www.fertibox.net/single-post/microbiologia-agricola

[4] Marín L., L. F., \& Jaramillo Colorado, B. E. (2015). Aislamiento de bacterias degradadoras de pesticidas organofosforados encontrados en suelos y en leche bovina. Revista Chilena de Nutrición, 42(2), 179-185. https://doi.org/10.4067/S0717-75182015000200010

[5] Quinchía, A., Gómez, F., Palencia Penagos, K., \& Giraldo Lopera, C. (2006). Evaluación de la de un aislado bacteriano nativo compatible con Pseudomona sp. al insecticida Lorsban 4 EC. Revista EIA, (5), 101-108. 
[6] Zapata, M. G, Lopera, M. Peñuela, G. Domíngez, M. (2005, Junio). Evaluación de la degradación del plaguicida clorpirifos en muestras de suelo utilizando el hongo Phanerochaete chrysosporium. Revista Facultad de Ingeniería, (33), 58-69.

[7] Barathidasan, K., Reetha, D., Milton, D. J., \& Govindammal, N. S. M. (2014). Biodegradación de clorpirifos por cocultivo de Cellulomonas fimi y Faneroqueto chrysosporium. Academic journals, 8(9), 961-966.

[8] Anwar, S., Liaquat, F., Khan, Q. M., Khalid, Z. M., \& Iqbal, S. (2009). Biodegradation of chlorpyrifos and its hydrolysis product 3,5,6-trichloro-2-pyridinol by Bacillus pumilus strain C2A1. Journal of Hazardous Materials, 168(1), 400-405.

[9] Gómez, S. Gútierrez, D. Hernández, A. Hernández, C. Losada, M. Mantilla, P. (2008, 9 enero- junio). Factores bióticos y abióticos que condicionan la biorremediación por Pseudomonas en suelos contaminados por hidrocarburos. NOVA. https://hemeroteca.unad.edu.co/index.php/nova/article/view/398/1158.

[10] CMGRD. (2016). Consejo Municipal para la Gestión del Riesgo de Desastres Municipio San Vicente del Caguán. Gobernacion de Caqueta, 139. https://caqueta.micolombiadigital.gov.co/sites/caqueta/content/files/000623/31140_pmgrd-san-vicente-del-caguan-final.pdf. 